This item was submitted to Loughborough's Research Repository by the author.

Items in Figshare are protected by copyright, with all rights reserved, unless otherwise indicated.

\title{
Estimation of ligament strains and joint moments in the ankle during a supination sprain injury
}

PLEASE CITE THE PUBLISHED VERSION

http://dx.doi.org/10.1080/10255842.2013.792809

\section{PUBLISHER}

(C) Taylor \& Francis

\section{VERSION}

AM (Accepted Manuscript)

\section{PUBLISHER STATEMENT}

This work is made available according to the conditions of the Creative Commons Attribution-NonCommercialNoDerivatives 4.0 International (CC BY-NC-ND 4.0) licence. Full details of this licence are available at: https://creativecommons.org/licenses/by-nc-nd/4.0/

\section{LICENCE}

CC BY-NC-ND 4.0

\section{REPOSITORY RECORD}

Wei, Feng, Daniel Tik-Pui Fong, Kai-Ming Chan, and Roger C. Haut. 2019. "Estimation of Ligament Strains and Joint Moments in the Ankle During a Supination Sprain Injury". figshare.

https://hdl.handle.net/2134/21285. 


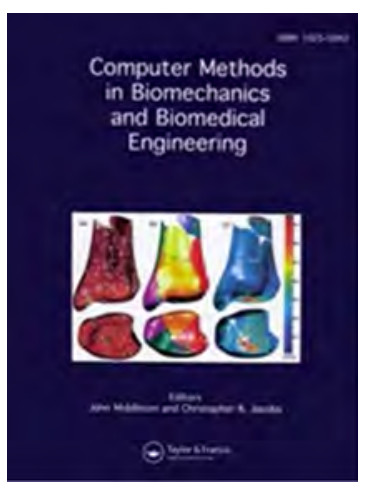

\section{Estimation of ligament strains and joint moments in the ankle during a supination sprain injury}

\begin{tabular}{|r|l|}
\hline Journal: & Computer Methods in Biomechanics and Biomedical Engineering \\
\hline Manuscript ID: & GCMB-2012-0287.R3 \\
\hline Manuscript Type: & Original Article \\
\hline Date Submitted by the Author: & 22-Jan-2013 \\
\hline Complete List of Authors: & $\begin{array}{l}\text { Wei, Feng; Rehabilitation Institute of Chicago, } \\
\text { Fong, Daniel; The Chinese University of Hong Kong, } \\
\text { Chan, Kai-Ming; The Chinese University of Hong Kong, } \\
\text { Haut, Roger; Michigan State University, }\end{array}$ \\
\hline Keywords: & $\begin{array}{l}\text { Anterior talofibular ligament, Ankle inversion sprain, Injury mechanism, } \\
\text { Ankle biomechanics, Computational model, Dynamic simulation }\end{array}$ \\
\hline &
\end{tabular}




\section{RESPONSES TO REVIEWERS' COMMENTS:}

\section{Manuscript ID GCMB-2012-0287.R2 (Computer Methods in Biomechanics and Biomedical Engineering): Estimation of ligament strains and joint moments in the ankle during a supination sprain injury}

We have revised the manuscript to address the reviewer's last concern. In the revised manuscript we first accepted all the changes made to address the reviewers' previous comments. We then tracked the new changes that directly respond to the reviewer's last critical comment. We want to thank the reviewer for the insightful suggestions that have made this work better.

\section{Reviewer(s)' Comments to Author:}

\section{Reviewer: 1}

15 Comments to the Corresponding Author Effect of variation on results of the value of the damping coefficient values must be added. Justification for not doing so, based on the existing study in the literature (lines 207-210) is not sufficient since that study looked at end range of motion where time effects (and thus damping) were not in play. This is not valid in your study.

We have varied the damping coefficient up and down one order of magnitude (similar to the study by Majors and Wayne, Ann Biomed Eng 39, 2807-2815, 2011) and found that joint moment calculated in the model changed by $0.45 \mathrm{Nm}$, approximately $2 \%$ of the maximum moment $(23 \mathrm{Nm})$ generated in the simulation. In addition, we have also varied the stiffness and

25 the exponent up and down one order of magnitude individually, just like Majors and Wayne (2011) in their study. The results showed that the joint moment was affected by approximately $1.5 \%$ and $4.3 \%$, respectively. All these analyses, however, provided no change in the strain results calculated in the model. We therefore believe that ligament strains, generated in linear elastic spring elements, were primarily affected by the prescribed bone motions in the current study, not by the contact parameters. We have included these analyses and results in Discussion of the revised manuscript on page 9, lines 205-214. Again, we would like to thank the reviewer for the suggestions that have made this study more informative. 


\title{
Estimation of ligament strains and joint moments in the ankle during a supination sprain injury
}

4

5

\author{
Feng Wei ${ }^{1,2}$, Daniel Tik-Pui Fong ${ }^{3,4}$, Kai-Ming Chan ${ }^{3,4}$, Roger C. Haut ${ }^{5}$ \\ ${ }^{1}$ Sensory Motor Performance Program \\ Rehabilitation Institute of Chicago \\ Chicago, IL 60611 \\ ${ }^{2}$ Department of Physical Medicine and Rehabilitation \\ Northwestern University Feinberg School of Medicine \\ Chicago, IL 60611 \\ ${ }^{3}$ Department of Orthopaedics and Traumatology \\ Prince of Wales Hospital \\ Faculty of Medicine, The Chinese University of Hong Kong \\ Hong Kong, China \\ ${ }^{4}$ The Hong Kong Jockey Club Sports Medicine and Health Sciences Center \\ Faculty of Medicine, The Chinese University of Hong Kong \\ Hong Kong, China \\ ${ }^{5}$ Orthopaedic Biomechanics Laboratories \\ Michigan State University \\ East Lansing, MI 48824 \\ Corresponding Author: \\ Prof Daniel Tik-Pui Fong \\ Department of Orthopaedics and Traumatology \\ Prince of Wales Hospital \\ Faculty of Medicine, The Chinese University of Hong Kong \\ Hong Kong, China \\ Tel: (852) 2632 3535, Email: dfong@ort.cuhk.edu.hk
}

Word Count: 234르 


\section{ABSTRACT}

41 This study presents the ankle ligament strains and ankle joint moments during an accidental

42 injury event diagnosed as a grade I anterior talofibular ligament (ATaFL) sprain. A male athlete

43 accidentally sprained his ankle while performing a cutting motion in a laboratory setting. The

44 kinematics data were input to a three-dimensional rigid-body foot model for simulation analyses.

45 Maximum strains in 20 ligaments were evaluated in simulations that investigated various

46 combinations of the reported ankle joint motions. Temporal strains in the ATaFL and the

47 calcaneofibular ligament (CaFL) were then compared and the three-dimensional ankle joint

48 moments were evaluated from the model. The ATaFL and CaFL were highly strained when the

49 inversion motion was simulated (10\% for ATaFL and $12 \%$ for $\mathrm{CaFL})$. These ligament strains

50 were increased significantly when either or both plantarflexion and internal rotation motions

51 were added in a temporal fashion (up to $20 \%$ for ATaFL and $16 \%$ for CaFL). Interestingly, at the

52 time strain peaked in the ATaFL, the plantarflexion angle was not large but apparently important.

53 This computational simulation study suggested that an inversion moment of approximately 23

$54 \mathrm{Nm}$ plus an internal rotation moment of approximately $11 \mathrm{Nm}$ and a small plantarflexion

55 moment may have generated a strain of $15-20 \%$ in the ATaFL to produce a grade I ligament

56 injury in the athlete's ankle. This injury simulation study exhibited the potentially important

57 roles of plantarflexion and internal rotation, when combined with a large inversion motion, to 58 produce a grade I ATaFL injury in the ankle of this athlete.

59

60 KEYWORDS: Anterior talofibular ligament, Ankle inversion sprain, Injury mechanism, Ankle biomechanics, Computational model, Dynamic simulation. 


\section{INTRODUCTION}

64 Ankle sprain is a common sports trauma (Fong et al., 2007). Over $80 \%$ of these injuries are 65 caused by excessive ankle joint supination which ruptures lateral ankle ligaments. Studies have 66 been conducted to describe the kinematics of accidental ankle sprains using motion or video 67 analysis (Kristianslund et al., 2011; Mok et al., 2011). These studies, however, do not provide 68 data on ankle ligament strains. Additionally, it has been suggested that deviation of the ground 69 reaction force away from the ankle joint center may result in an explosive ankle joint moment 70 causing injury (Fong et al., 2009a). Such a moment would trigger a twisting motion to stretch 71 ligaments vigorously (Delahunt et al., 2006).

73 An investigation by Fong et al. (2009b) of a grade I supination injury to the anterior talofibular

74 ligament (ATaFL) has revealed that, in addition to plantarflexion and rearfoot inversion, internal 75 rotation of the foot was noted to be greater than previously reported (Bahr et al., 1998). 76 However, the roles of inversion, plantarflexion, and internal rotation, or their temporal 77 combination on lateral ligament strains are still unclear. Recently, Wei et al. (2011b) has 78 developed a computational model and utilized motion analysis-based kinematic data from

79 laboratory tests to drive the model for estimations of dynamic ankle ligament strains and joint 80 moments (Wei et al., 2011a). The model has shown its ability to help in the study of the motions 81 that may predispose ankle ligaments to injury during external foot rotation. The purpose of the 82 current study was to use this model to study the motions producing ankle ligament strains and 83 joint moments during the accidental sprain event documented by Fong et al. (2009b). Since the 84 injury was diagnosed as a grade I ATaFL sprain, and a combination of inversion, plantarflexion, 
85 and internal rotation has been documented, a high strain in this ligament and high joint moments 86 in these three directions were expected.

87

88 METHODS

$89 \quad$ Injury case

90 A male athlete (23 years, $1.75 \mathrm{~m}, 62.6 \mathrm{~kg}$ ) wore a pair of high-top basketball shoes and 91 performed a series of cutting motion trials in the laboratory. In one trial the athlete accidentally 92 sprained his right ankle, and the injury was immediately diagnosed as a grade I sprain of the 93 ATaFL by a well-trained orthopaedic specialist (K.M.C.). The injury occurred in the laboratory 94 that utilized marker-based motion and model-based image-matching video analysis systems 95 (Fong et al., 2009b).

96 Computational modeling

97 A 3D multi-body dynamic foot model (Wei et al., 2011b) was utilized for simulations of the 98 injury event. The model comprised five segments, namely the tibia, fibula, talus, calcaneus, and 99 tarsal and metatarsal bones. Details of model development and validation have been previously 100 described (Wei et al., 2011b). The model was constructed from a generic cadaver ankle (male, 19 101 years, $1.88 \mathrm{~m}, 86 \mathrm{~kg}$ ) which was scanned using computed tomography (CT) in a neutral position 102 and with a separation of $0.6 \mathrm{~mm}$ between slices. CT images were converted into 3D models in 103 MIMICS (Materialise, Ann Arbor, MI) and imported into dynamic rigid-body motion simulation 104 software (SolidWorks, TriMech Solutions, LLC, Columbia, MD) (Iaquinto and Wayne, 2010; 105 Liacouras and Wayne, 2007). The neutral position of the ankle from the CT scan was maintained 106 in the model. The model includes 20 ligaments formulated as linear elastic, tension only springs 107 (Figure 1) with their stiffnesses $(\mathrm{N} / \mathrm{mm}$ ) adapted from the literature (Table 1). The slack length 
108 of the ligaments was defined with the model positioned in neutral. An initial strain of $2 \%$, 109 implemented by inserting a spring element of length $2 \%$ shorter than the initial length (distance 110 between insertion points), was assigned to each ankle ligament (Wei et al., 2011a), thereby 111 inducing an in situ preload in the ligament. An initial strain of $0.5 \%$, however, was applied to the 112 interosseous ligaments (Liacouras and Wayne, 2007). The ground was simulated as a rigid 113 platform in the software. The 3D contacts (Iaquinto and Wayne, 2010) were implemented 114 between adjacent bones as well as between the bones and ground plate in order to prevent 115 overlap during the simulation. This was done by calculating the interference at each time step 116 and applying an outward force if any overlap was detected. The magnitude of the force $F$ was a 117 function of material stiffness $k(10,000 \mathrm{~N} / \mathrm{mm})$, penetration depth $g$, exponent $e(1.75)$, 118 penetration velocity, and damping coefficient $c(400 \mathrm{Ns} / \mathrm{mm})$, with the penetration at maximum 119 damping set to its lowest allowable value $(d=0.001 \mathrm{~mm})$.

$$
F=k g^{e}+\left(\frac{d g}{d t}\right) f(c, d)
$$

121 Friction was neglected to simulate cartilage effects. In the model the tibia was only allowed to 122 move vertically (one degree of freedom). The fibula, talus, and calcaneus were allowed to move 123 in all six degrees of freedom, leaving bone motion to be a function of ligament behavior, surface 124 contact, and external perturbations. For simplification purposes, the remaining bones of the foot 125 (tarsal and metatarsal bones) were fused together and moved as a unit, with its motion primarily 126 dependent on motions of the talus and calcaneus.

127 128 129 Injury simulation 
130 At the beginning of the simulation, three times body weight $(1840 \mathrm{~N})$ was applied to the 131 proximal end of the model to simulate dynamic weight bearing (Cavanagh and Lafortune, 1980), 132 distributing one-sixth of the load on the fibula and the rest on the tibia (Lambert, 1971; Wei et 133 al., 2011b). The 3D, temporal kinematic data from the case report (Fong et al., 2009b), i.e. 134 inversion-time data, plantarflexion-time data, and internal rotation-time data, were used as input 135 for simulations (Wei et al., 2011a). These actual motions placed the neutral foot model in the 136 starting position of the athlete's ankle in order to begin the simulation. Three motor elements 137 were used to drive the motion of the bones, two on the talus for plantarflexion and internal 138 rotation, respectively, and one on the calcaneus for inversion. The three axes of rotation were set 139 as: (1) dorsi-plantarflexion - fixed to the talus through its estimated center and initially oriented 140 medial-lateral; (2) internal-external rotation - along the tibial axis; and (3) inversion-eversion 141 fixed to the calcaneus through its estimated center and perpendicular to the previous two 142 (initially oriented anteroposterior) (Figure 1). These axes of rotation were based on a joint 143 coordinate system (Wu et al., 2002), as the same system was utilized to calculate the injurious 144 kinematics (Fong et al., 2009b). To systematically investigate the contribution of each motion 145 and their combinations, four motion simulations were performed: (1) pure inversion; (2) 146 inversion plus plantarflexion; (3) inversion plus internal rotation; and (4) a combination of 147 inversion, plantarflexion, and internal rotation. The SolidWorks Motion package from the 148 simulation software was used to execute these simulations. Continuous rotation-time data were 149 interpolated (using the Akima Spline method) into the SolidWorks Motion to drive the talus 150 and/or the calcaneus movement. Ligament strains were estimated from the model (Iaquinto and 151 Wayne, 2011; Wei et al., 2011b). Resistive moments, deduced by inverse dynamics from the 152 motors along the three axes of rotation, were also obtained from the model analysis. 


\section{$154 \quad$ RESULTS}

155 Under inversion alone, the CaFL was strained the most at 12\% (Figure 2). The ATaFL and 156 LTaCL were strained to approximately $10 \%$. When temporal plantarflexion or internal rotation 157 was added, both the CaFL and ATaFL were strained to approximately $14-16 \%$. With all three 158 motions combined the ATaFL was strained the most at $20 \%$ followed by the CaFL at $16 \%$. 159 Temporal strain profiles of the ATaFL and CaFL were compared, along with the foot motions 160 and ankle joint moments (Figure 3). There was a switch in magnitude of strains from the CaFL to 161 the ATaFL at $0.16 \mathrm{~s}$ after footstrike (heel strike). The highest moment was $23 \mathrm{Nm}$ for inversion 162 followed by $11 \mathrm{Nm}$ for internal rotation (Figure 3c).

\section{DISCUSSION}

165 A grade I ankle sprain is characterized as minimal tearing of ligament fibers (Noyes et al., 1989). 166 Rupture strain of ankle ligaments can be estimated in the range of 30-35\% (Beumer et al., 2003; 167 Funk et al., 2000). Ligament collagen fibers are thought to tear when half of the rupture strain is 168 reached (Yahia et al., 1990). The ATaFL strain in the current study reached 15-20\%, which is 169 approximately one-half of the suggested rupture strain. Previous studies also report that a $10 \mathrm{Nm}$ 170 external moment applied to the foot will cause pain and discomfort, and an external moment of 171 41-45 Nm generates ankle fractures (Markolf et al., 1989). By investigating a supination injury 172 case, the current study indicated that an ankle joint moment up to $23 \mathrm{Nm}$ may produce a grade I 173 ankle sprain.

174 
175 Clinically the mechanism of an ankle supination sprain has been associated with a combination 176 of inversion and plantarflexion. In contrast, Kristianslund et al. (2011) and Mok et al. (2011) 177 suggest the important role of internal rotation. Mok et al. (2011) also suggest that future designs 178 of injury prevention measures may only need to consider inversion and internal rotation. Yet, the 179 current study showed that either plantarflexion or internal rotation, when added to inversion, 180 increased the ATaFL strains from $10 \%$ to approximately $15-16 \%$. And the temporal combination 181 of all three motions raised the ATaFL strain to over 20\% (Figure 2), suggesting that, in addition 182 to inversion, both plantarflexion and internal rotation may be important in generating supination 183 ankle sprains, as estimated by this one case study.

185 While a few studies have presented constant stiffnesses for ankle ligaments (Attarian et al., 1985; 186 Siegler et al., 1988), nonlinear and viscoelastic behavior in those ligaments has been observed 187 (Attarian et al., 1985; Funk et al., 2000). Ankle ligament strains under a physiological range of 188 ankle motion are thought to be in the range of 5-10\% (Colville et al., 1990; Ozeki et al., 2002). 189 Funk et al. (2000) reported the ankle ligament force-strain curves have a typical toe region up to $1906 \%$ strain followed by a loading region (nearly linear) up to $20 \%$ strain. Although the linear 191 approximation used in the current study may have underestimated ankle ligament strains, the 192 error was likely minimal (within 3\%) for a strain range of $16-20 \%$, while larger errors (up to $19350 \%$ ) could be involved for strains less than 15\% (Funk et al., 2000). Additionally, a previous 194 study by others has concluded that a viscoelastic assumption of the ankle ligaments could be 195 neglected for very slow $(<0.0001 / \mathrm{s})$ or very fast $(>1 / \mathrm{s})$ strain rates, but substantial effects may 196 exist on ligament behavior for intermediate strain rates (Funk et al., 2000). The modeled 
197 ligaments in the current study experienced strain rates approximately in the range of $1-1.5 / \mathrm{s}$, 198 implying that the viscoelasticity of those ligaments may be negligible.

200 Other assumptions of the model and the simulation should also be noted. Firstly, the tarsal and 201 metatarsal bones were fused together and moved as a unit in the model for simplification 202 purposes. Although the ligaments connecting the tarsal and metatarsal bones may be less 203 important than those listed in Table 1, this fusion could have caused an overestimation of the 204 joint moments calculated from the model, especially for the internal rotation moment. Secondly, 205 model sensitivity to the parameters chosen to define the contact was evaluated by individually varying the stiffness, exponent, and damping coefficient up and down one order of magnitude, similar to a previous study by others the impact of damping coefficients, chosen to define the eontact, on bone motion and ligament strain was not investigated in the current study. However a recent study, by others, using a similar modeling approach to study the wrist biomechanics varies the contact parameters up and down-one order of magnitude and concludes little $(<1 \%)$ to no ehange in range of motion of the wrist predicted by the model(Majors and Wayne, 2011). Joint moment was most affected by the exponent term (4.3\%) followed by the damping parameter $(2.0 \%)$ and the stiffness value (1.5\%). Varying these parameters provided no change in the ligament strain results predicted by the model. Thirdly, a constant weight bearing load was used in the current study due to the unavailability of ground reaction force (GRF) data from the case 216 report. In addition, this constant load was applied in the beginning of simulation, not at 217 heelstrike, because the time for the GRF to reach its maximum was unknown. Future 218 experimental studies with use of a force plate may provide detailed GRF data (both magnitude 219 and duration) so that a simulated weight bearing load could be applied at footstrike. Finally, the 
220 effect of a lack of the proximal tibiofibular joint in the model on potential alterations of the ankle 221 stability is currently unknown.

222

223 While this computational ankle model has provided insights into motions responsible for ankle 224 injury by simulating both in vitro (Wei et al., 2012; Wei et al., 2010) and in vivo experiments 225 (Wei et al., 2011a), it has been based on only a generic model, without potential effects of the 226 musculature. Therefore joint moments may have been underestimated (Wei et al., 2011a). 227 Additionally, the effects of anatomical differences between the injured subject and the cadaver 228 ankle used to build the model are unknown. Future studies that investigate ankle injury 229 mechanisms and prevention strategies may want to build subject-specific models, incorporate 230 muscle effects, and potentially integrate the nonlinear and viscoelastic responses of ankle 231 ligaments.

232

233 ACKNOWLEDGEMENTS

234 The authors thank Dr. Seungik Baek from Michigan State University for providing the MIMICS 235 software.

236 


\section{REFERENCES}

238 Attarian DE, McCrackin HJ, DeVito DP, McElhaney JH, Garrett WE, Jr. 1985. Biomechanical 239 characteristics of human ankle ligaments. Foot Ankle 6(2):54-58.

240 Bahr R, Pena F, Shine J, Lew WD, Engebretsen L. 1998. Ligament force and joint motion in the 241 intact ankle: a cadaveric study. Knee Surg Sports Traumatol Arthrosc 6(2):115-121.

242 Beumer A, van Hemert WL, Swierstra BA, Jasper LE, Belkoff SM. 2003. A biomechanical 243 evaluation of the tibiofibular and tibiotalar ligaments of the ankle. Foot Ankle Int 244 24(5):426-429.

245 Cavanagh PR, Lafortune MA. 1980. Ground reaction forces in distance running. J Biomech $246 \quad 13(5): 397-406$.

247 Colville MR, Marder RA, Boyle JJ, Zarins B. 1990. Strain measurement in lateral ankle 248 ligaments. Am J Sports Med 18(2):196-200.

249 Delahunt E, Monaghan K, Caulfield B. 2006. Altered neuromuscular control and ankle joint 250 kinematics during walking in subjects with functional instability of the ankle joint. $A m J$ 251 Sports Med 34(12):1970-1976.

252 Fong DT, Chan YY, Mok KM, Yung P, Chan KM. 2009a. Understanding acute ankle 253 ligamentous sprain injury in sports. Sports Med Arthrosc Rehabil Ther Technol 1:14.

254 Fong DT, Hong Y, Chan LK, Yung PS, Chan KM. 2007. A systematic review on ankle injury 255 and ankle sprain in sports. Sports Med 37(1):73-94.

256 Fong DT, Hong Y, Shima Y, Krosshaug T, Yung PS, Chan KM. 2009b. Biomechanics of 257 supination ankle sprain: a case report of an accidental injury event in the laboratory. $A m J$ $258 \quad$ Sports Med 37(4):822-827. 
259 Funk JR, Hall GW, Crandall JR, Pilkey WD. 2000. Linear and quasi-linear viscoelastic 260 characterization of ankle ligaments. J Biomech Eng 122(1):15-22.

261 Iaquinto JM, Wayne JS. 2010. Computational model of the lower leg and foot/ankle complex: 262 application to arch stability. J Biomech Eng 132(2):021009.

263 Iaquinto JM, Wayne JS. 2011. Effects of surgical correction for the treatment of adult acquired 264 flatfoot deformity: a computational investigation. J Orthop Res 29(7):1047-1054.

265 Kristianslund E, Bahr R, Krosshaug T. 2011. Kinematics and kinetics of an accidental lateral $266 \quad$ ankle sprain. J Biomech 44(14):2576-2578.

267 Lambert KL. 1971. The weight-bearing function of the fibula. A strain gauge study. J Bone Joint $268 \quad$ Surg Am 53(3):507-513.

269 Liacouras PC, Wayne JS. 2007. Computational modeling to predict mechanical function of 270 joints: application to the lower leg with simulation of two cadaver studies. J Biomech Eng 271 129(6):811-817.

Majors BJ, Wayne JS. 2011. Development and validation of a computational model for investigation of wrist biomechanics. Ann Biomed Eng 39(11):2807-2815.

Markolf KL, Schmalzried TP, Ferkel RD. 1989. Torsional strength of the ankle in vitro. The supination-external-rotation injury. Clin Orthop Relat Res (246):266-272.

Mok KM, Fong DT, Krosshaug T, Engebretsen L, Hung AS, Yung PS, Chan KM. 2011. Kinematics analysis of ankle inversion ligamentous sprain injuries in sports: 2 cases during the 2008 Beijing Olympics. Am J Sports Med 39(7):1548-1552.

Noyes FR, Grood ES, Torzilli PA. 1989. Current concepts review. The definitions of terms for motion and position of the knee and injuries of the ligaments. J Bone Joint Surg Am $71(3): 465-472$. 
282 Ozeki S, Yasuda K, Kaneda K, Yamakoshi K, Yamanoi T. 2002. Simultaneous strain 283 measurement with determination of a zero strain reference for the medial and lateral ligaments of the ankle. Foot Ankle Int 23(9):825-832.

285 Pfaeffle HJ, Tomaino MM, Grewal R, Xu J, Boardman ND, Woo SL, Herndon JH. 1996. Tensile 286 287 properties of the interosseous membrane of the human forearm. J Orthop Res 14(5):842845.

Siegler S, Block J, Schneck CD. 1988. The mechanical characteristics of the collateral ligaments of the human ankle joint. Foot Ankle 8(5):234-242.

Wei F, Braman JE, Weaver BT, Haut RC. 2011a. Determination of dynamic ankle ligament strains from a computational model driven by motion analysis based kinematic data. $J$ Biomech 44(15):2636-2641.

Wei F, Hunley SC, Powell JW, Haut RC. 2011b. Development and validation of a computational model to study the effect of foot constraint on ankle injury due to external rotation. Ann Biomed Eng 39(2):756-765.

Wei F, Meyer EG, Braman JE, Powell JW, Haut RC. 2012. Rotational stiffness of football shoes influences talus motion during external rotation of the foot. $J$ Biomech Eng 134(4):041002.

Wei F, Villwock MR, Meyer EG, Powell JW, Haut RC. 2010. A biomechanical investigation of ankle injury under excessive external foot rotation in the human cadaver. J Biomech Eng 132(9):091001.

303 Cristofolini L, Witte H, Schmid O, Stokes I. 2002. ISB recommendation on definitions of 
1

2

3

4

304

305

306 Yahia L, Brunet J, Labelle S, Rivard CH. 1990. A scanning electron microscopic study of rabbit

307 ligaments under strain. Matrix 10(1):58-64.

joint coordinate system of various joints for the reporting of human joint motion--part I:

ankle, hip, and spine. International Society of Biomechanics. J Biomech 35(4):543-548.

\section{8}

309

14

15

17

18

19

20

21

22

23

24

25

26

27

28

29

30

31

32

33

34

35

36

37

38

39

40

41

42

43

44

45

46

47

48

49

50

51

52

53

54

55

56

57 


\section{FIGURE LEGENDS}

311 Figure 1: Posterior (a), medial (b), and lateral (c) views of the ankle model showing the axes of 312 rotation used in the simulations (dotted lines in a and b) and the locations of 16 simulated 313 ligaments (c): the interosseous ligaments (IOL-I and IOL-II); the anterior and posterior 314 tibiofibular (ATiFL and PTiFL); the calcaneofibular (CaFL); the anterior and posterior 315 talofibular (ATaFL and PTaFL); the anterior and posterior tibiotalar (ATiTL and PTiTL); the 316 tibionavicular (TiNL); the talonavicular (TaNL); the calcaneocuboid (CaCL); the 317 calcaneonavicular (CaNL); the medial, central, and lateral plantar fascia (MPF, CPF, and LPF). 318 For clarity, the lateral, interosseous, medial, and posterior talocalcaneal ligaments (LTaCL, 319 ITaCL, MTaCL, and PTaCL) between the talus and the calcaneus were set invisible. Ligament 320 initial length and stiffness were documented in Table 1.

321 Figure 2: Maximum strains estimated from the model in various selected ligaments ( $>2 \%$ strain) 322 for different ankle motions.

323 Figure 3: Normalized kinematic data from Fong et al. (2009b) were re-plotted (a). Values were 324 normalized between their initial and peak measures, i.e. plantarflexion: $-23.6^{\circ} \sim 1.0^{\circ}$; inversion: $32515.6^{\circ} \sim 47.6^{\circ}$; internal rotation: $-12.3^{\circ} \sim 10.0^{\circ}$. Temporal profiles of strains $(\mathrm{b})$ in the ATaFL and 326 CaFL, and ankle joint moments (c) during the injury incident were estimated from the model by 327 applying a combination of inversion, plantarflexion, and internal rotation simultaneously. 
329 TABLE

330 Table 1: Twenty ligaments were simulated in the model. The initial length was the length prior

331 to the application of an in situ strain. The stiffness was adapted from Wei et al. (2011b).

\begin{tabular}{|c|c|c|c|}
\hline Ligament names & Abbreviation & $\begin{array}{l}\text { Initial length } \\
(\mathrm{mm})\end{array}$ & Stiffness (N/mm) \\
\hline Interosseous I & IOL-I & 18.0 & 400 (Pfaeffle et al., 1996) \\
\hline Interosseous II & IOL-II & 17.2 & 400 (Pfaeffle et al., 1996) \\
\hline Anterior Tibiofibular & ATiFL & 18.1 & 90 (Siegler et al., 1988) \\
\hline Posterior Tibiofibular & PTiFL & 22.7 & 90 (Beumer et al., 2003) \\
\hline Calcaneofibular & $\mathrm{CaFL}$ & 41.3 & 70 (Liacouras and Wayne, 2007) \\
\hline Anterior Talofibular & ATaFL & 32.2 & 90 (Siegler et al., 1988) \\
\hline Posterior Talofibular & PTaFL & 18.8 & 70 (Liacouras and Wayne, 2007) \\
\hline Anterior Tibiotalar & ATiTL & 18.0 & 70 (Liacouras and Wayne, 2007) \\
\hline Posterior Tibiotalar & PTiTL & 16.0 & 80 (Liacouras and Wayne, 2007) \\
\hline Tibionavicular & TiNL & 39.3 & 40 (Siegler et al., 1988) \\
\hline Talonavicular & TaNL & 11.0 & 70 (Liacouras and Wayne, 2007) \\
\hline Interosseous Talocalcaneal & ITaCL & 8.7 & 70 (Liacouras and Wayne, 2007) \\
\hline Lateral Talocalcaneal & LTaCL & 12.2 & 70 (Liacouras and Wayne, 2007) \\
\hline Medial Talocalcaneal & MTaCL & 8.5 & 70 (Liacouras and Wayne, 2007) \\
\hline Posterior Talocalcaneal & PTaCL & 29.9 & 70 (Liacouras and Wayne, 2007) \\
\hline Calcaneocuboid & $\mathrm{CaCL}$ & 26.2 & 70 (Liacouras and Wayne, 2007) \\
\hline Calcaneonavicular & $\mathrm{CaNL}$ & 26.7 & 70 (Liacouras and Wayne, 2007) \\
\hline Medial Plantar Fascia & $\mathrm{MPF}$ & 147.9 & 200 (Iaquinto and Wayne, 2010) \\
\hline Central Plantar Fascia & $\mathrm{CPF}$ & 146.5 & 230 (Iaquinto and Wayne, 2010) \\
\hline Lateral Plantar Fascia & LPF & 133.2 & 180 (Iaquinto and Wayne, 2010) \\
\hline
\end{tabular}




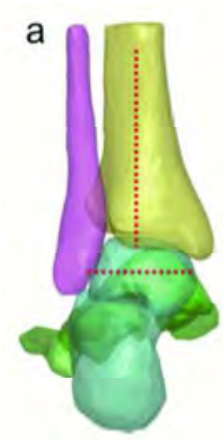

\section{b}

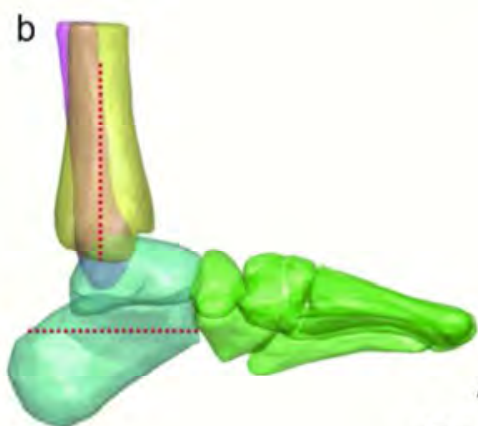

c
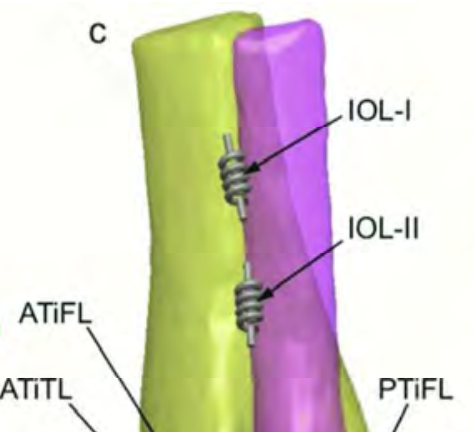

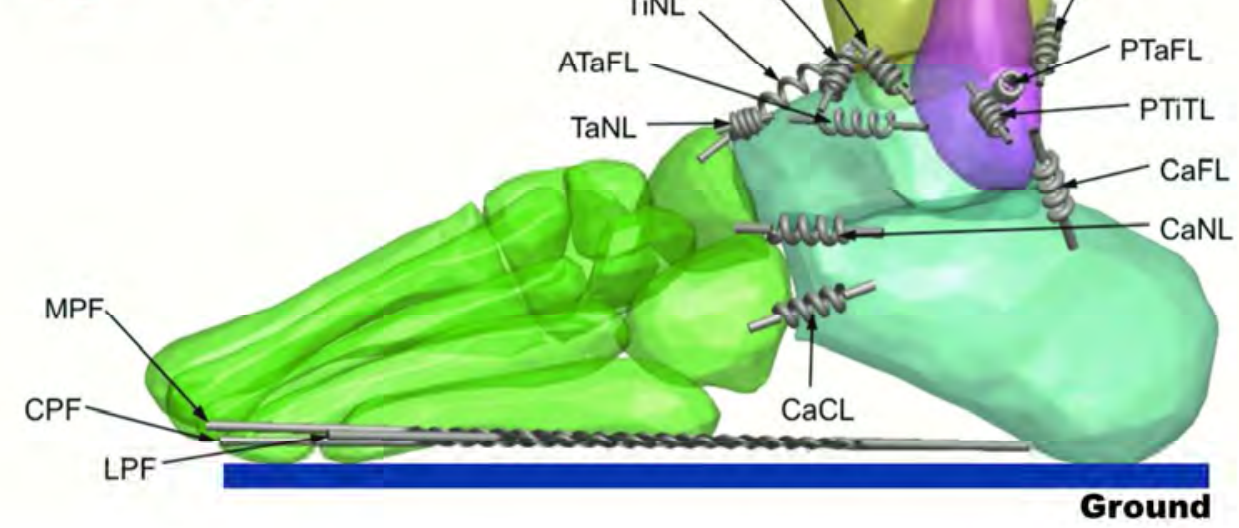

Posterior (a), medial (b), and lateral (c) views of the ankle model showing the axes of rotation used in the simulations (dotted lines in $a$ and $b$ ) and the locations of 16 simulated ligaments (c): the interosseous ligaments (IOL-I and IOL-II); the anterior and posterior tibiofibular (ATiFL and PTiFL); the calcaneofibular (CaFL); the anterior and posterior talofibular (ATaFL and PTaFL); the anterior and posterior tibiotalar (ATiTL and PTiTL); the tibionavicular (TiNL); the talonavicular (TaNL); the calcaneocuboid (CaCL); the calcaneonavicular (CaNL); the medial, central, and lateral plantar fascia (MPF, CPF, and LPF). For clarity, the lateral, interosseous, medial, and posterior talocalcaneal ligaments ( $L T a C L, I T a C L, M T a C L$, and PTaCL) between the talus and the calcaneus were set invisible. Ligament initial length and stiffness were documented in Table 1. $127 \times 97 \mathrm{~mm}(300 \times 300$ DPI $)$ 


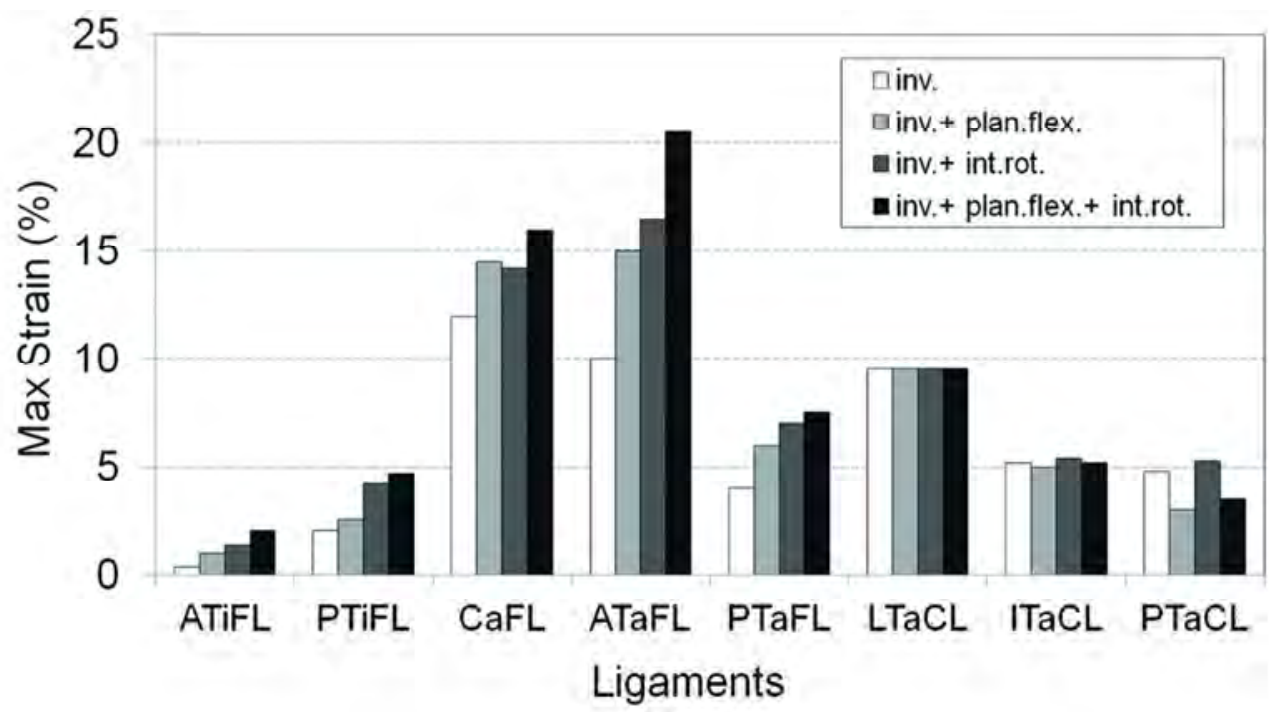

Maximum strains estimated from the model in various selected ligaments ( $>2 \%$ strain) for different ankle motions. $48 \times 26 \mathrm{~mm}(600 \times 600$ DPI $)$ 
Normalized kinematic data from Fong et al. (2009b) were re-plotted (a). Values were normalized between their initial and peak measures, i.e. plantarflexion: $-23.6^{\circ} \sim 1.0^{\circ}$; inversion: 15.60 47.60; internal rotation: $12.3^{\circ} \sim 10.0^{\circ}$. Temporal profiles of strains (b) in the ATaFL and CaFL, and ankle joint moments (c) during the injury incident were estimated from the model by applying a combination of inversion, plantarflexion, and internal rotation simultaneously. $240 \times 524 \mathrm{~mm}(300 \times 300$ DPI $)$ 